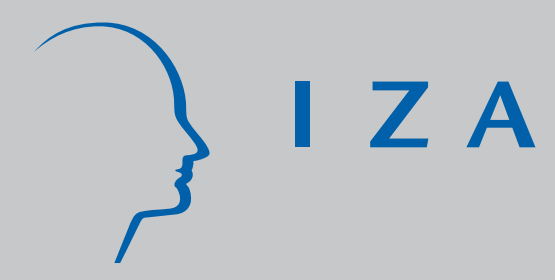

IZA DP No. 755

In Support of the Supporters? Do Social

Forces Shape Decisions of the Impartial?

Thomas J. Dohmen

April 2003 


\title{
In Support of the Supporters? Do Social Forces Shape Decisions of the Impartial?
}

\author{
Thomas J. Dohmen \\ IZA Bonn
}

Discussion Paper No. 755

April 2003

\author{
IZA \\ P.O. Box 7240 \\ D-53072 Bonn \\ Germany \\ Tel.: +49-228-3894-0 \\ Fax: +49-228-3894-210 \\ Email: iza@iza.org
}

This Discussion Paper is issued within the framework of IZA's research area General Labor Economics. Any opinions expressed here are those of the author(s) and not those of the institute. Research disseminated by IZA may include views on policy, but the institute itself takes no institutional policy positions.

The Institute for the Study of Labor (IZA) in Bonn is a local and virtual international research center and a place of communication between science, politics and business. IZA is an independent, nonprofit limited liability company (Gesellschaft mit beschränkter Haftung) supported by the Deutsche Post AG. The center is associated with the University of Bonn and offers a stimulating research environment through its research networks, research support, and visitors and doctoral programs. IZA engages in (i) original and internationally competitive research in all fields of labor economics, (ii) development of policy concepts, and (iii) dissemination of research results and concepts to the interested public. The current research program deals with (1) mobility and flexibility of labor, (2) internationalization of labor markets, (3) welfare state and labor market, (4) labor markets in transition countries, (5) the future of labor, (6) evaluation of labor market policies and projects and (7) general labor economics.

IZA Discussion Papers often represent preliminary work and are circulated to encourage discussion. Citation of such a paper should account for its provisional character. A revised version may be available on the IZA website (www.iza.org) or directly from the author. 
IZA Discussion Paper No. 755

April 2003

\title{
ABSTRACT \\ In Support of the Supporters? \\ Do Social Forces Shape Decisions of the Impartial? *
}

\begin{abstract}
Analyzing the neutrality of referees during nine German premier league (1. Bundesliga) soccer seasons, this paper documents evidence that social forces influence agents' preferences and decisions. Those, who are appointed to be impartial, tend to favor the home team as they systematically award more injury time in close matches when the home team is behind. Further evidence for similar home bias comes from referees' wrong, or at least disputable, decisions to award goals and penalty shots. The severity of social pressure, measured by the crowd's composition and proximity to the action, determines its effect. Not all agents are affected by social pressure to the same degree.
\end{abstract}

JEL Classification: J00, M50

Keywords: favoritism, principal-agent relationship, personnel economics

Thomas J. Dohmen

Institute for the Study of Labor (IZA)

P.O. Box 7240

53072 Bonn

Germany

Tel.: +49 22838940

Fax: +492283894210

Email: dohmen@iza.org

\footnotetext{
* I am grateful to IMP AG for providing the data. I would like to thank especially Holger Rahlfs and Joern Wendland for their cooperation. I am also indebted to the DFB, particularly to Klaus Low, for providing detailed information on financial rewards for referees and their evaluation. I thank Ben Kriechel, Winfried Koeniger, and Steven Levitt for comments and suggestions. This work has also benefited from contributions of seminar participants at Maastricht University, the University of Chicago, and IZA in Bonn. All errors are mine.
} 


\section{Introduction}

This paper documents empirically that social forces influence agents' decisions by analyzing the behavior of referees in German professional soccer. The social atmosphere leads agents (here the referees) to take actions that are neither in the interest of their principal (the German soccer association $(\mathrm{DFB}))$ nor - from an objective point of view - in the agent's own interest. The results indicate that social pressure elicits favoritism among soccer referees even though this might hurt their chances to be re-appointed. This has important implications for principal-agent relations, because the existence of such favoritism implies that it can be optimal for the principal to deprive the agent of his discretion when social forces influence the agent to take actions that result in undesired outcomes. Despite its significance for agency theory, favoritism has not been widely studied in theoretical work (see Prendergast and Topel, 1996, for a notable exception) and rarely been the focus of empirical work. ${ }^{1}$

Empirically it is usually difficult, if not impossible, to undeniably identify favoritism that leads to a mis-allocation of resources. Situations of concern to economists in which favoritism can potentially reduce efficiency are usually complex. Even if evidence for favoritism is found, it is often difficult to convincingly argue that it results in inefficient outcomes. For example, a promotion of a worker that is based purely on favoritism might be an optimal allocation if the good work relations between the favored worker and his supervisor outweigh any productivity advantage of contestants. Such problems paired with the difficulty to obtain the required sensitive data explain the scarcity of empirical work.

To circumvent these difficulties, I use data on the behavior of referees in German premier league (1. Bundesliga) professional soccer matches to address the question whether agents' decisions are affected by the social environment and if so, whether they systematically favor a team although the principal appoints them to be impartial. Not being neutral is also not in the private interest of a referee as it reduces his re-appointment probability. The data cover all 2754 matches in 9 seasons from the 1992/93 season up to and including the 2000/2001 season. They record information on the length of extra time awarded at the end of each period of the match, on the correctness of decisions to award penalty shots and goals, as well as information on the relative performance of teams, and on other crucial events in the match (e.g. the timing of goals, substitutions, injury treatments, cards, etc.).

\footnotetext{
${ }^{1}$ Only recently, Garicano, Palacios and Prendergast (2001) have taken a similar empirical approach as this paper using data from Spanish soccer.
} 
Section 2 describes the data in more detail. Section 3 explains the relation between the German soccer association and its referees. Section 4 shows that referees tend to favor the home team by lengthening the match when the home team is slightly behind at the end of the match. While this is consistent with the finding of Garicano, Palacios and Prendergast (2001), I do not find evidence that referees shorten matches in which the home team is slightly ahead. I then extend the analysis to drawn matches finding that the allowance for time lost is longer when the home team is more likely to score next and shorter when the match is not exciting. I assess whether all referees are biased and analyze the impact of the crowd's composition and its proximity to the field on referee behavior. Section 5 finds further evidence of favoritism analyzing whether referees systematically award more disputable penalty shots to the home team. The percentage of correct penalty shot decisions for the home team is smallest when the home team is one goal behind. Beyond, referees award almost twice as many penalty shots to the home team, which might suggest that referees deny the visiting team a correct penalty shot more often. But since I lack the data to satisfactorily check this hypothesis, I confine the analysis to the share of correct penalty shot decisions given the absolute number of penalty shots awarded. Section 6 summarizes and concludes.

\section{The Data}

The data were made available to me for scientific research by IMP AG, a German company, that collects data for a soccer data base. I use data on the premier German soccer league (1. Bundesliga), in which 18 teams determine the national soccer champion, by far the most important cup in German professional soccer. A season consists of 34 rounds with 9 matches each (306 matches per season) so that teams play each other twice a season, once in the first 17 rounds and once in the last 17 rounds when the status of home and visiting team is reversed. Typically, there is one round per week. About 6 matches take place on Saturdays and the others on Fridays or Sundays. ${ }^{2}$ As laid down by the International Football Association Board (FIFA) in Law 7 of the Laws of the Game (see FIFA, 2002), a match lasts for two 45-minute periods. According to this Law, "[a]llowance is made in either period for all time lost through: substitution(s), assessment of injury to players, removal of injured players from the field of play for treatment, wasting time, any

\footnotetext{
${ }^{2}$ Sometimes a round is scheduled during the week, usually on Tuesdays and Wednesdays, because there are sometimes too few weekends available for scheduling games.
} 
other cause. ${ }^{3}$ The allowance for time lost is at the discretion of the referee." (FIFA, 2002, p. 19).

The winner of a match has been awarded two points until the 1994/1995 season, but has received three points since the 1995/1996 season; the loser has never gotten points. When a match ends in a draw, each team receives one point. The league ranking is based on the number of points. Among teams with the same number of points the one with the biggest difference between goals scored and goals received is higher ranked. If teams are identical in this respect as well, the team that has scored most goals is higher ranked. The team ranked first at the end of the season wins the championship. The lowest 3 ranked teams descend to the second highest league (2. Bundesliga) and are replaced by the top 3 ranked teams from the 2 . Bundesliga. There are also incentives to finish 2nd to 5th, or even lower, as these ranks qualify for participation in various European Cups, the most lucrative and prestigious of which is the UEFA Champions League. ${ }^{4}$

I have information on all 2754 matches of the 9 seasons from the 1992/93 season up to and including the 2000/2001 season. These data record the date, destination and outcome of the match, the number of spectators, the referee's name, as well as the information on various events and their timing during the game, including goals scored, penalty shot called, or yellow cards and red cards called. Variables constructed on the basis of video recordings indicate whether the referee's decision concerning the penalty shot or goal

\footnotetext{
${ }^{3}$ The rules regarding the number of substitutions have changed during the observation period. Until 1994/95, teams could only substitute 2 player during a match. In 1994/95, each team could replace the goalie in addition to the two players. Since 1995/96, teams can substitute 3 players (including the goalie).

${ }^{4}$ The number of teams that can take place in various competitions on a European level in the next season depends on the past relative performance of German teams in these competitions. The first and the second ranked German team automatically qualify for the Champions League, which replaced the European Champion Clubs' Cup in time for the 1992/93 season. The third ranked team can take part in qualifying rounds for the Champions League. If eliminated the team does not qualify, it competes in the UEFA Cup. In addition, at least 3 slots for the UEFA Cup have been allotted to German teams throughout the observation period. (At times, Germany was allotted even 4 slots.) These slots have been filled by the teams ranked 4th to 6th in the Bundesliga until the 1999/2000 season when the UEFA Cup Winners' Cup, for which Cup winners qualified, was abandoned. If the Cup winner happened to be eligible for the UEFA Cup competition because of its league ranking, the team that ranked immediately after the teams qualified for the UEFA Cup. Since 1999/2000, the 3 UEFA Cup slots are filled by the German Cup winner and the teams ranked 4 th and 5 th in the league. Furthermore, three additional teams (ranked directly behind the teams qualified for the UEFA Cup) have the possibility to enter the UEFA Cup via winning UEFA Intertoto Cup. Additional slots for the UEFA Champions League or the UEFA CUP might be allotted if a German team wins one of these competitions.
} 
was correct. Several match statistics, like each team's shots on goal, fouls, crosses, etc., are provided separately for both periods of the match together with the allowance for time lost at the end of the first period and at the end of the second period.

\section{The Referees and the German Football As- sociation (DFB)}

German premier soccer league referees are appointed by the German Football Association (DFB), which is organized in 5 regional associations (Regionalverbände) consisting of 21 different smaller associations (Landesverbände). Referees must be a member of a club that is organized in a regional association. Requirements for becoming a referee include the completion of a course and passing a written and physical test. Referees usually start in the lowest division and after having been promoted to referee in the Landesliga, the fifth division, they can be promoted at most one division each year if judged qualified by official observers. Since 1995, the number of Bundesliga-referees is limited to 22. Before that, the DFB appointed up to 36 referees each season. In total, 69 umpires have refereed at least one 1. Bundesliga game during all 9 seasons for which the data is available.

Financial incentives for refereeing a Bundesliga match are large and have risen substantially over time. From July 1992 (i.e. when the observation period begins) until July 1997 referees received 2500 DM per game, from August 1997 until July 2000 they were paid 4000 DM per game, and since August the reward is $6000 \mathrm{DM}$ per game. In addition, travel expenses (including hotel and transportation) have been covered since $1992 .{ }^{5}$ The agent, i.e. the referee, clearly has strong pecuniary incentive to be re-appointed by the principal, the DFB, who commands referees to be impartial. Being biased is not in the referee's private interest, because it leads, if detected, the DFB to sack a referee. ${ }^{6}$

The performance of referees is monitored and judged by an official observer of the DFB referee committee, who attends the match in the stadium and fills a performance evaluation form afterwards. The first aspect addressed in the evaluation is the referee's appearance during the game, in particular whether the referee was decided, secure, and had the courage to take unpopular decisions, or whether he was impressed by complaining players. As all

\footnotetext{
${ }^{5}$ Before July 1992, referees received a monthly lump-sum payment of 520 DM, as well as a lump-sum payment of 100 DM per match to cover expenses and transportation expenses. The information on referee renumeration was provided by the DFB.

${ }^{6}$ This was confirmed by the DFB upon request.
} 
these points concern how referees deal with the social environment on the field, performance in a social environment seems to be a critical issue for the evaluation and appointment of referees. However, these evaluations pay no explicit attention to whether the referee's preferences are shaped by the social environment created by the crowd. ${ }^{7}$ Whether social pressure produced by the crowd even leads a referee to deviate from being impartial is the center of attention in this paper.

The second and third points of the evaluation form concern how well the referee interpreted the Laws of the Game and additional instructions. Item 3.3 of the evaluation form concerns the correct translation of instructions into action. This includes whether the referee's allowance for time lost is adequate, as is clearly stated by Linn (2003). Linn (2003) also interprets "wasting time" as including delays in carrying out throw-ins, corner kicks, goal kicks, or free kicks, as well as impeding a quick restart of play. Referees can loose their position upon poor performance. ${ }^{8}$

\section{Social Forces, Favoritism and Injury Time}

This section analyzes whether there is evidence for systematic bias in the allowance for time lost in the German data and whether the referee's preference to award overtime is influenced by the social environment created by the crowd. To do this, I classify matches according to the score difference at the end of the regular period of 45 minutes, which is calculated by subtracting the number of goals scored by the visitor from the number of goals scored by the home team. I then check whether the length of injury time depends on the size of the score difference and on its sign (i.e. on whether the home or the visiting team is ahead in the score). ${ }^{9}$ I start by presenting kernel density

\footnotetext{
${ }^{7}$ See Becker and Murphy (2000) for a treatise on how social forces shape the preferences of agents.

${ }^{8}$ According to an official of the DFB, this happens regularly in lower level leagues, but is a very rare event incase of Bundesliga-referees. The DFB does not state officially why a referee is not re-appointed. In addition, our data do not allow us to distinguish between voluntary quits and dismissals.

${ }^{9}$ This approach follows Garicano et al. (2001) report evidence from two Spanish soccer seasons that referees systematically favor home teams by shortening matches in which the home team is one goal ahead and lengthening matches in which the home team is one goal behind at the end of regular time. The analysis in this paper goes far beyond replicating Garicano et al. (2001) - which would be justified in its own right, not least because Spanish soccer has been suspect of corruption - as I base the evidence on more observations, account for referee and team fixed effects, assess whether biased and unbiased referees co-exist, and investigate whether more allowance for time lost is made in drawn matches when the home team is more likely to score next. Besides, more detailed information for each match allows
} 
estimates of the distribution of allowance for time lost in the second period for various score differences in order to give a visual impression of a potential dependence relation between the outcome of the match and the allowance for time lost. Next, I examine this dependence relation more closely in a regression analysis of matches in which either the home team or the visiting team is exactly one goal ahead at the beginning of injury time. I then assess whether more injury time is awarded in drawn matches in which the home team is more likely to score next. Given the evidence for favoritism, I explore whether all referees are biased. And finally, I test whether the crowd's size, composition and proximity to the field influence the degree of favoritism.

\subsection{A Visual Impression}

Figure 1 plots kernel density estimates of the distribution of allowance for time lost in the second half by scoreline. The scoreline is calculated as the difference between goals scored by the home team and goals scored by the visiting team. The figure reveals some interesting results.

[Figure 1 here]

The allowance for time lost in the second half is larger the closer the match. Most additional time is awarded when the home team is one goal behind, and second most when the home team is one goal ahead. Yet, the distribution of additional time awarded when the home team is one goal behind in score stochastically dominates the densities of injury time in all other situations. This suggests the existence of favoritism towards the home team. Interestingly, distributions of for allowance of time lost in the first half - i.e. when there is less at stake with another halftime to score - are similar for all scorelines. ${ }^{10}$

The evidence that German referees systematically favor the home team is however somewhat weaker than that reported for Spanish soccer referees. First, the size of the referees' bias - a mean difference of 21 additional seconds awarded when the home team is 1 goal behind rather than 1 goal ahead is much smaller than the bias reported by Garicano et al. (2001), who find a mean difference of about 113 seconds. Second, contrary to Garicano et al. (2001) there is no evidence that referees shorten close matches when the

me to control for the relative performance in the match itself.

${ }^{10}$ The estimated distributions are not presented here, but are available from the author upon request. 
home team is ahead. ${ }^{11}$ Figure 1 reveals instead that extra-time is then even longer than in drawn matches. This result might be explained by the fact that more supporters accompany their team to away matches in Germany, where home cities of opponents are less far apart than is Spain. This issue is addressed below.

The distributions of additional time awarded in drawn matches and matches in which one of the teams is ahead in score by two goals are very similar. But strikingly, means and variances of the estimated probability density functions for additional time in decided games, in which one of the teams is leading by three or more goals, are much smaller. This suggests that referees lengthen exciting games.

The inspection of the raw data concerning the relation between the allowance for time lost and the scoreline of the match suggests that referees' decisions to favor the home team and lengthen exiting matches conform the preferences of the crowd. Spectators like suspense (see also Chan, Courty and $\mathrm{Li}, 2002$ ) and the supporters of the home team, who typically make up for the majority of the crowd, like the home team to win or at least to draw the match. However, it is possible that the observed distributions of additional time awarded at the end of each half obey the rules. To analyze this, I next control for factors that should objectively determine the allowance for time lost.

\subsection{A Closer Look at Close Games}

Table 1 documents that referees allow 20 seconds more additional time on average when the home team is 1 goal behind compared to games in which the home team is leading by 1 goal (see column [1]). This difference in mean duration of matches is extremely robust and does not disappear even if I control for factors that should affect, according to the Laws of the Game, the amount of extra time awarded at the end of each half. The size and statistical significance of the home bias as measured by the coefficient on the "Home Ahead" dummy, which is 1 if the home team is one goal ahead and 0 if the home team is one goal behind, remains virtually unchanged when more controls for the number of treatments, substitutions and cards, as well as other potentially confounding factors are added to the regression model (see columns [2] - [7]). Although the number of actual injury treatments on the

\footnotetext{
${ }^{11}$ Clearly, the results would be closer to Garicano's et al. (2001) if referees would shorten rather than lengthen matches when the visitor is one goal behind. The difference between allowance for time lost in matches in which the home team is one goal behind and drawn matches (42 seconds more when the home team is one goal behind) is quite comparable to that reported by Garicano et al. (2001).
} 
field has the expected effect of prolonging the game, the effect is small (1.4 seconds, see column [2]) and it becomes weaker and statistically insignificant when more controls are added (columns [3] - [7]). A similar observation holds for the number of substitutions. The number of cards, which can be viewed as a proxy for the intensity of the match and is thus expected to be positively correlated with appropriate allowance for time lost, has the expected sign. A yellow card leads to about 6 seconds of extra-time. This result is also robust. Controls for the teams' relative strength and performance in the match do not affect the estimates in any notable way.

Allowance for time lost in the second half is on average bigger after 1997. This suggests that the revision of the Laws by the International Football Association Board (IFAB) in 1997 induces referees to prolong the allowance for time lost, even though the DFB neither introduces a Fourth Official, nor changed its instructions for referees. ${ }^{12}$ But the size of the home bias is not affected by controls for season-specific effects. Yet, the existence of seasonspecific effects raises the question, whether the pattern observed in Figure 1 is the same across all seasons. Figure 2 plots the estimated kernel densities of second-half injury in close and drawn matches for each season separately. ${ }^{13}$

\section{[Figure 2 here]}

An inspection of the figure reveals that the injury time distribution of matches in which the home team is one goal behind, lies to the right of all other distributions in all but the 1992/93, 1995/96 and 1998/99 seasons. Univariate regressions for each season of extra time on a score-difference dummy (just like in column [1] of Table 1) indicate that games, in which the home team is behind, last significantly longer in all but these three seasons, in which is the difference is smaller and statistically not significant. ${ }^{14}$ In the

\footnotetext{
${ }^{12}$ The revised Laws permit the appointment of a Fourth Official, an off-field observer who assists the referee. In international games, the Fourth Official indicates the number of the minimum minutes of injury time in the last minute of regular playing time. However, the DFB has not introduced a Fourth Official, an off-field observer who assists the referee, until the year 2003.

${ }^{13}$ For other score differences, I find a similar pattern as in Figure 1, except that the injury time distributions for decided matches (score difference $>|2|$ ) is more skewed to the right in the last three seasons.

${ }^{14}$ In the 1995/1996 season, matches last insignificantly longer when visitors are ahead. This is remarkable since the 1995/96 season marks the change in the rewards for winning, as a victory yields 3 points rather than 2 points from that season onwards. If referees favor the home team, they should become more likely to shorten matches in which the home team is 1 goal ahead, because the home crowd is expected to put more intense pressure
} 
other seasons, the estimated difference in additional time ranges from 43.3 seconds in the 1994/95 season to 21.0 seconds in the $1997 / 98$ season.

The home bias in awarding injury time is generally much smaller (and barely significant) at the end of the first half, while various explanatory variables including actual treatments and the number of yellow cards have similar effects (see Table 2). This result supports the conjecture that the referee is influenced by social pressure exerted by the crowd, which is probably less intense, i.e. earsplitting, after the first half when fans can put their faith, that their team reverses the score, in the coming second half.

Social pressure exerted by the crowd is likely to increase not only towards the end of the game, but also towards the end of the season, when more is at stake. Therefore I tested for the existence of an "end-of-season-effect", which presumes that the difference in injury time awarded in close matches is larger towards the end of the season. While I do find that this difference widens by about 10 seconds in the last 5 rounds compared to earlier rounds, the effect is statistically insignificant and its size diminishes as more controls are added..$^{15}$

\subsection{More Evidence from Games Ending in a Draw}

If referees favor the home team, we expect them to lengthen drawn matches when the home team is more likely to score next. Table 3 finds some evidence for this conjecture. Allowance for time lost increases when the home team tied the match, i.e. is likely to be stronger towards the end of the game. This effect disappears when more direct controls for strength are introduced. However, measures of relative strength also indicate that more time is allowed when the home team is stronger. The weakness of such measures like shots on goal or won tackles is that they can only proxy for average relative strength during the entire game. To the extent that these relative measures are still a good indicator of a team's superiority during injury time, the estimates indicate that the match is likely to last longer when the home team is

on the referee. This should on average increase the difference in second-half injury time in close games. Garicano et al. (2001) report evidence for this conjecture finding a negative coefficient for the interaction between the score difference (which takes the value -1 when the home team is one goal behind and 1 if it is one goal ahead) and a dummy which is one in the season in which the 3-points rule applies. Replicating their analysis using the 1994/95 season (the one just preceding the change in rewards) and the 1995/96 season, I find a significant positive (about 22 seconds) effect of the interaction term. It should be noted, however, that if I had picked other pairs of pre- and post-change seasons, I would have found exactly the result that Garicano et al. (2001) report.

${ }^{15}$ When all controls as in Table 1 , column [7], are included, the difference widens by 6 seconds. 
relatively stronger. For example, the referee ends the match later the higher is the home teams relative number of shots on the goal. This effect is significant in the specification in column [5] of Table 3. Other measures like the relative number of crosses and the relative number of tackles won also have a positive sign, but are statistically not significant.

An intriguing result documented in by Table 3 is that referees seem to lengthen more exiting drawn matches - just as is true for exciting matches in which one of the teams is leading (cf. Figure 1). Games in which neither team has scored (0:0 Score) end about 10 seconds earlier on average than other matches that end in a draw at the end of regular time. Moreover, matches with more shots on goal, more tackles and more crosses last longer.

\subsection{Are All Referees Biased?}

In order to assess whether agents are influenced by the social environment to different degrees, I compare the size of the average individual home bias in close matches across referees. To reduce the amount of randomness in the calculations, I restrict the comparison to referees who have umpired at least five matches in which the home team was one goal ahead at the end of regular time and five matches in which the visitor was one goal ahead.

To control for differences in the amount of injury time that should objectively have been awarded, I regress second-half injury time on the number of treatments, cards and substitutions in the second half as well as on season dummies and attribute the residuals to the referee's discretion. A referee's magnitude of home bias is then calculated as the difference between his average discretionary injury time awarded when either the home or the visiting team is one goal ahead at the end of regular time.

Table 4 suggests that biased and unbiased referees coexist. But although the point estimates of the individual bias in column 1 of Table 4 give rise to this conjecture, strong statistical support is lacking as the standard deviations of the amount of injury time awarded in columns 3 and 6 are too large to make strong statements at sensible significance levels. ${ }^{16}$

\subsection{Social Pressure from the Crowd?}

Until now it has been taken for granted that the crowd in the stadium prefers the home team to win and likes exiting matches to last longer. I have conjectured that the crowd creates a particular atmosphere, i.e. social environment,

\footnotetext{
${ }^{16}$ Not reported in the table is the fact that the average injury time for all referees is shortest for decided matches followed by drawn matches or matches with 2 goals difference, and is longest in close games.
} 
in the stadium (e.g. by shouting, complaining, etc.) that puts social pressure on the referee to adjust his preferences accordingly. The relation between the strength of the home crowd's incentives to exert pressure on the referee and the referees' decisions have been considered by distinguishing between close games and decided games, by making out differences between decisions in the first and the second half, and by considering the stage of the season. Next, I will assess whether the size and composition of the crowd, as well as amount of pressure that can be created impact on the degree of favoritism.

The amount of social pressure that is created depends on the magnitude of the crowd's relative preferences for a home team victory and the extent to which these relative preferences can be conveyed. How strong relative preferences are, depends on the relative number of home team supporters. How vigorously the home team supporters can express their preferences might depend on the size of the crowd or the attendance to capacity ratio. Moreover, the social atmosphere might also depend on the architecture of the stadium, especially how close supporters are to the field. To explore how referees are affected by the social atmosphere, I augment the regression models from Table 1, columns [6] and [7], by controls for the absolute number of spectators, the attendance to capacity ratio, and interactions of these variables with an indicator for the score difference ("Score Difference") that takes on the value 1 if the home team is one goal ahead and -1 if it is one goal behind. At the same time, exploiting the fact that a track separates the field and the ranks in some stadiums, I estimate the regression models separately for sub-samples of matches that were played in stadiums with a track (columns [1] and [2] of Table 5) and those that took place in stadiums without a track (columns [3] and [4] of Table 5), because the existence of a track might affect to what extent the crowds' articulated preferences "reach" the referee.

Intriguingly, the difference in injury time awarded in close matches is estimated to be statistically insignificant in stadiums with a track, but much larger and significant in stadiums in which the crowd is physically closer to the referee. The estimated home bias amounts to almost 1 minute (twice the coefficient on "Score Difference") of additional overtime when the home team is one goal behind rather than ahead. Neither the number of spectators, nor the attendance to capacity ratio seem to have a significant effect on the length of injury time. More important yet, both factors do not seem to affect the home bias significantly, as the estimated coefficients for the interaction terms with the score difference suggest. However, a higher attendance to capacity ratio tends to reduce the home bias in stadiums without a track and to increase it in stadiums with a track. In fact, the apparent difference of the size of the home bias in stadiums with and without a track disappears 
when the interaction terms are dropped. ${ }^{17}$

A closer inspection of regression models, in which both, none or only one interaction term is included, reveals that the home bias in stadiums with a track is reduced more the more spectators are in the stadium. The pure size of the crowd is much less important in stadiums with a track. However, there, the attendance to capacity ratio matters as the home bias is larger the fewer seats remain empty. ${ }^{18}$ The general finding that the home bias is affected differently by the pure number of spectators might stem from differences in the composition of the crows. For example, we would expect the home bias to fall with a higher attendance when it is predominately caused by more supporters of the visiting team being present in the stadium.

Since the data do not contain information about crowd composition, I propose proxies and assess how well they perform in explaining attendance. First, supporters of teams are usually concentrated in the proximity of the team's home city. These fans who live close to the team's home city are more likely to attend away-matches when the travelling distance to the opponent's stadium is small. Based on coordinates I calculated the distance between home cities of the opponents of a game. ${ }^{19}$ Second, the number of supporters of the visiting team is likely to depend on the team's nationwide popularity. I proxy for a team's general popularity by the number of fans it attracts when playing away from home. Therefore, I calculate for each team the average attendance to capacity ratio in the stadium when the team is the visitor. ${ }^{20}$ This proxy is expected to be correlated with the number of fans that supports the team when it plays away from home. It covers especially the fans of the team's supporters that live relatively close to where the away-match takes place, but might live far away from the city where the team is vested. ${ }^{21}$

\footnotetext{
${ }^{17}$ This also corresponds with an inspection of the raw data, because separate kernel density estimates of injury time in close matches for stadiums with and without a track suggest a similar magnitude of home bias in both situations.

${ }^{18}$ The results of this section are important as they help to reject the potential critique that the referee behaves in the interest of the principal, who might judge it advantageous for economic reasons (i.e. a higher attendance rate, more public interest) when the home team wins or when exiting matches last longer. Such desired referee bias would then balance out over a season as each team plays every other team once at home and once abroad. It is difficult to argue, however, that the DFB has an interest in favoring specific teams depending on the stadium they play in.

${ }^{19}$ This was done using the program on the webpage http://www.koordinaten.de/online/dist_wel.shtml.

${ }^{20} \mathrm{An}$ inspection of the popularity ranking of teams according to this measure suggests that it is a surprisingly good measure. The highest four ranked teams are FC Bayern München, Borussia Dortmund, Schalke 04 and Borussia Mönchengladbach.

${ }^{21}$ For example, this proxy is expected to cover Bayern München supporters who live in the North of Germany rather than close to Munich and support Bayern when it plays in
} 
If these proxies really affect the number of visiting team supporters, they also affect total attendance, i.e. if the visiting team is a very popular team or if the visiting team's home city is not too far away, the number of visiting team supporters and hence the total number of fans in the stadium should rise. To assess this, I regress the absolute deviation from average attendance of the home team's home matches on the proxy for the visiting team's nationwide popularity and the distance between the opponents' home cities. ${ }^{22}$ Since the effect of distance on the willingness to travel might not be linear I estimate a piecewise constant step function to capture the effect of distance on attendance. The results in Table 6 indicate that both the popularity of the visiting team (as proxied by its ability to fill stadiums in away matches) and the distance between cities of opposing teams have a significant impact on deviations from average attendance. This implies that popularity and proximity to the stadium affect attendance and hence the number of supporters of the visiting team. The effect of distance is non-linear. While regular attendance rises on average by 4906 if the visiting team is vested less than 150 $\mathrm{km}$ away, there is no statistically significant increase at longer distances.

To assess whether the size of the home bias depends on the composition of the crowd, I augment the regression model from Table 1, column [7], by an interaction term between the score difference and a dummy variable that takes the value 1 if the visiting team's relative popularity is in the upper third of the distribution. Relative popularity is calculated as the ratio of the team's general popularity (i.e. the average attendance in matches played away from home, see above) to the general attendance of matches on the home team's turf. The latter is calculated as the average attendance to capacity ratio in home games. To account for the impact of distance between the cities of the opponents, I estimate the regression model separately for matches in which both teams come from cities that are less than $150 \mathrm{~km}$ apart, and cities which are further apart. In the former case, it is suspected that a large fraction of the crowd supports the visiting team. The regression results in Table 7 show that the home bias is then negligible and statistically equal to zero if the distance between the cities is less than $150 \mathrm{~km}$, no matter how popular the visiting team is (see column [1]). When the cities are further than $150 \mathrm{~km}$ apart, the home bias is significant and large, especially when the visiting team's general popularity is not particularly large (about 30 seconds, see column [2]). However, when the visiting team is popular, such that it

\footnotetext{
Hamburg.

${ }^{22}$ To avoid introducing correlation between the error term of the regression and the explanatory variables, I do not include observations with the respective home team and visiting team when calculating average attendance and the attractiveness of the visiting team.
} 
generally attracts many fans in matches played away from home relative to the average attendance in the home team's stadium, the bias becomes significantly smaller (about 20 seconds smaller). These results support the conjecture that the referees' decisions are influenced by the preferences of the crowd.

\section{$5 \quad$ Are Penalty Decisions Subject to Favoritism?}

Since it might be argued that adding additional time does not have a big impact on the outcome of a match as only 0.04 goals are scored on average in each minute of injury time, I extend the study of favoritism to an examination of referees' decisions to award penalty shots. Penalty kicks lead to goals in $78 \%$ of the cases in the data, so that a biased penalty decision has a much more immediate and severe consequence on the outcome of the match than granting extra time. I examine, whether the decision to award a penalty shot to a team depends on the score in the match at the time when the penalty shot decision is taken, and whether there are discernible differences for home teams and visitors. Although awarding a penalty shot when it was not justified and not awarding a penalty shot when it should have been awarded both have strong effects on the outcome of the game, I will only deal with the first type of situation due to lack of data.

I report the fraction of penalty shots that were wrongly awarded, correctly awarded or that were disputable for the home team in Table 8 and the visiting team in Table 9. A comparison of the tables reveals that more than twice as many penalty shots were awarded to the home team. But since we do not observe how many penalty shots were not awarded although they should have been awarded, I will not consider this as prima facie evidence for home bias. Tentative evidence for home bias is however the fact that the fraction of correctly awarded penalty shots is smaller for the home team $(67.55 \%$ vs $71.25 \%$ ) than for the visitor. This difference is due to a higher fraction of "disputable" penalty shot decisions rather than to wrong decisions. This suggests that referees are reluctant to take obviously wrong decisions, probably because they fear stronger repercussions on their re-appointment probability. However, when the decision is difficult, potentially because the referees sight is restricted or the situation demands some judgement, referees seem to use their discretion more in favor of the home team. Even more striking is the fact that referees seem to take more wrong and disputable decisions in favor of the home team when the match is drawn $(35.15 \%)$ or when the home team is behind in score. However, it must be noted that referees also take more disputable decisions in favor of the visitor, when the visitor is just 
one goal behind. This corresponds with the findings relating to injury time, which showed that referees also award more injury time when the visitor is one goal behind in score than in decided games.

To get an impression of the impact of the crowd on penalty decisions, I calculated the average number of penalties shots for the home and the visiting team that were awarded in stadiums with a track and without a track. A first remarkable finding is that more penalties are awarded in stadiums without a track: 0.280 penalties per match in matches that took place in stadiums without a track as opposed to 0.255 per match in matches played in stadiums with a track. Second, while the average number of penalty shots for the visiting team is similar in both types of stadiums (0.086 if there is a track and 0.088 if there is no track), home teams that play in stadiums with a track receive more penalties per match (0.192 as opposed to 0.169). The effect might be spurious, for example because teams, that play such that they receive many penalty shots in any game, happen to have a home stadium with a track. To check this, I calculate for each team the difference between average penalties awarded per match played at home and away from home. I then regress this difference on a constant and a dummy variable that takes the value one if the home team plays in a stadium with a track. The estimated coefficient (-0.02) in a regression with 31 observations (i.e. the number of teams in the sample) indicates that teams, whose home stadium has no track, get fewer penalties in home matches relative to away matches than teams who play their home matches in stadiums with a track.

\section{Conclusion}

I have shown that social forces can influence agents to take decisions that are not in their private interest. I provided empirical evidence that referees' decisions in German professional soccer are influenced by the preferences of the crowd. The social atmosphere in the stadium leads referees into favoritism although being impartial is optimal for them to maximize their re-appointment probability. Conform with the preferences of the crowd, they lengthen exiting games and favor the home team by allowing most time when the home team is behind by one goal and by prolonging a drawn match when the home team is more likely to score next. This difference is most severe in stadiums in which the physical distance between the referee and the crowd is smallest and when relatively fewer supporters of the visiting team attend the game.

These findings have important implication for the principal-agent relation in economics. The evidence of the existence of favoritism and the fact that economic agents adjust their preferences in social interactions, e.g. by 
incorporating the utility of the social environment in their own utility function (social pressure) explains the existence and importance of formal rule structures in large organizations and therefore must be a major concern for labor economists as well as organization economists.

\section{References}

Becker, G. S., And K. M. Murphy (2000): Social Economics. Market Behavior in a Social Environment. Harvard University Press, Cambridge, MA.

Chan, W., P. Courty, and H. Li (2002): "Suspense," Working Paper, London Business School.

FÉdÉration Internationale De Football Association (FIFA) (2002): Laws of the Game. Fédération Internationale de Football Association, Zurich, Switzerland.

Garicano, L., I. Palacios, and C. Prendergast (2001): "Favoritism Under Social Pressure," NBER Working Paper 8376.

Linn, G. (2003): "Ziel und Ablauf von Schiedsrichterbeobachtungen," DFB Schiedsrichter-Zeitung, 1.

Prendergast, C., And R. Topel (1996): "Favoritism in Organizations," Journal of Political Economy, 104(5), 958-978. 


\section{Figures and Tables}

Figure 1: Kernel Density Estimates of the Second-Half Injury Time For Various Score Differences

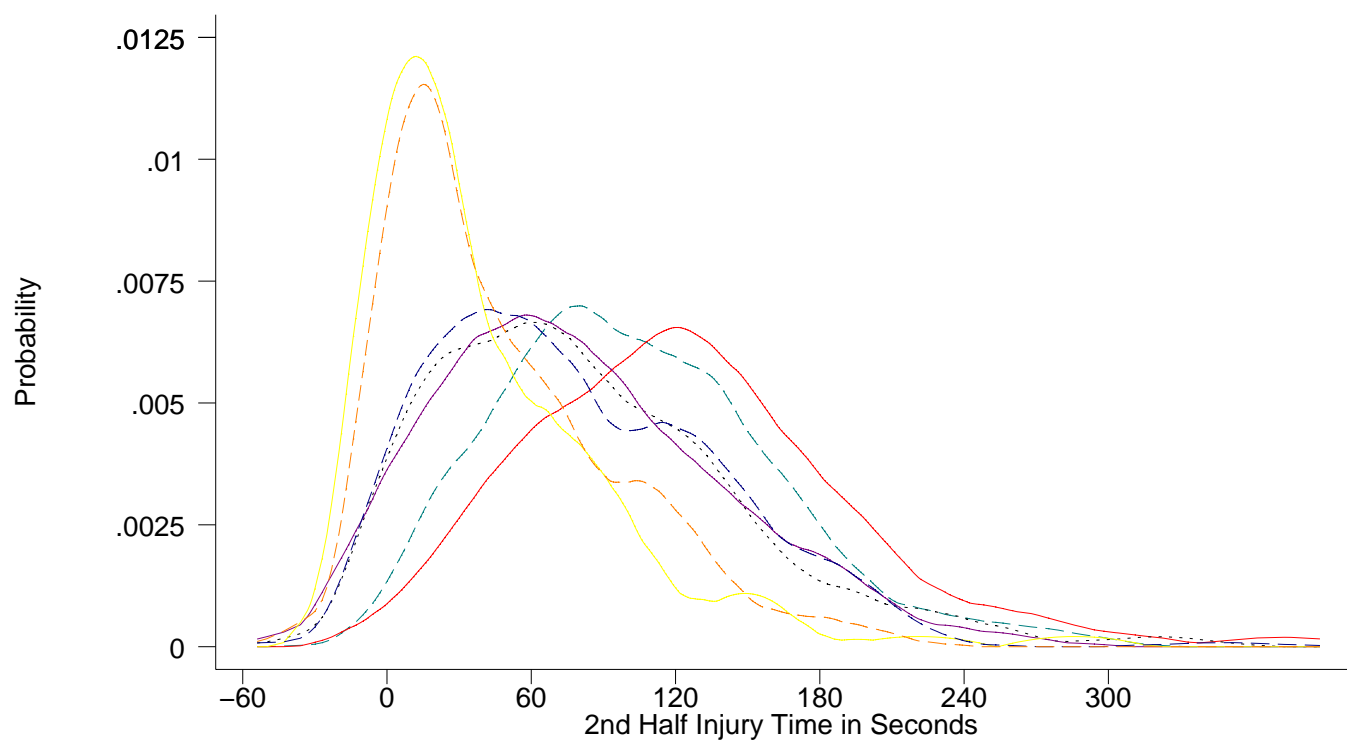

Lines are dashed for the kernel density estimates of the injury time distributions in matches in which the home team is ahead in score and solid when the home team is behind. The kernel density estimates of the injury time distribution in drawn matches is plotted with a dotted line. The lines are light (yellow and orange) if the score difference exceeds 2 goals, dark (purple and dark blue) if the score difference is 2 goals, and medium light (red and green) if the absolute value of the score difference is 1. 
Figure 2: Kernel Density Estimates of the Second-Half Injury Time in Close Games for Different Seasons
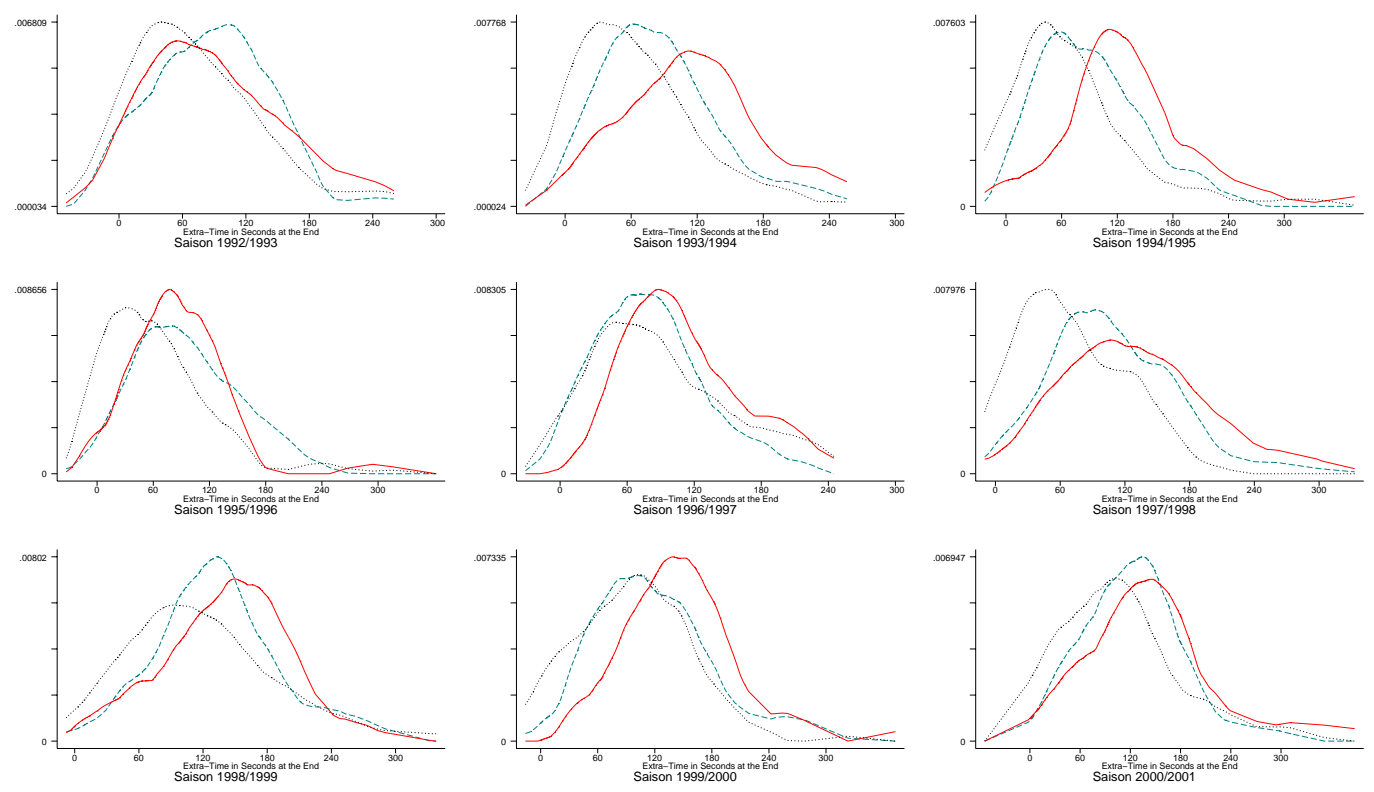

The Figure plots for each season kernel density estimates of the injury time distributions in close games, i.e. matches in which the home team is either ahead by one goal in score (dashed green line), or behind (solid red line), or matches that are drawn (dotted black line). 
Table 1: Length of Second-Half Injury Time in Close Games

The dependent variable is the length of second-half injury time (in seconds) in matches in which one team was leading by one goal after regular time. "Home Ahead" takes the value 1 if the home team is one goal ahead and zero if the home team is one goal behind.

\begin{tabular}{|c|c|c|c|c|c|c|c|}
\hline & {$[1]$} & {$[2]$} & {$[3]$} & {$[4]$} & {$[5]$} & {$[6]$} & {$[7]$} \\
\hline Home Ahead & $\begin{array}{c}\mathbf{- 1 9 . 9 7 8} \\
{[4.976]^{* *}}\end{array}$ & $\begin{array}{c}\mathbf{- 2 0 . 0 7 2} \\
{[5.051]^{* *}}\end{array}$ & $\begin{array}{l}\mathbf{- 2 1 . 2 4 1} \\
{[4.769]^{* *}}\end{array}$ & $\begin{array}{l}\mathbf{- 2 0 . 7 7 6} \\
{[4.808]^{* *}}\end{array}$ & $\begin{array}{l}\mathbf{- 2 1 . 1 1 7} \\
{[5.001]^{* *}}\end{array}$ & $\begin{array}{l}\mathbf{- 2 2 . 2 1 5} \\
{[5.218]^{* *}}\end{array}$ & $\begin{array}{l}\mathbf{- 2 2 . 0 2 5} \\
{[5.245]^{* *}}\end{array}$ \\
\hline \multirow[t]{2}{*}{ No. Treatments } & & 1.37 & 0.835 & 0.243 & 0.335 & 0.298 & 0.628 \\
\hline & & {$[0.436]^{* *}$} & {$[0.432]$} & {$[0.386]$} & [0.393] & {$[0.423]$} & {$[0.440]$} \\
\hline \multirow[t]{2}{*}{ No. Substitution } & & 5.529 & 5.095 & 0.282 & 1.1 & 0.161 & 1.847 \\
\hline & & {$[1.678]^{* *}$} & {$[1.671]^{* *}$} & {$[2.210]$} & {$[2.384]$} & {$[2.429]$} & {$[2.171]$} \\
\hline \multirow{2}{*}{ No. Yellow Cards } & & & 7.481 & 7.581 & 7.654 & 8.094 & 7.07 \\
\hline & & & {$[1.208]^{* *}$} & {$[1.181]^{* *}$} & {$[1.206]^{* *}$} & {$[1.357]^{* *}$} & {$[1.564]^{* *}$} \\
\hline \multirow{2}{*}{ No. 2nd Yellow } & & & 0.547 & -1.592 & -2.126 & -1.429 & -1.716 \\
\hline & & & {$[4.499]$} & {$[4.062]$} & {$[4.277]$} & {$[4.446]$} & [4.403] \\
\hline \multirow[t]{2}{*}{ No. Red Cards } & & & 8.713 & 10.446 & 11.288 & 10.892 & 10.424 \\
\hline & & & [8.246] & {$[7.789]$} & [7.653] & {$[7.066]$} & [6.890] \\
\hline \multirow[t]{2}{*}{ Season 1993} & & & & 2.662 & 19.267 & 25.974 & 10.483 \\
\hline & & & & {$[7.672]$} & {$[10.877]$} & {$[12.676]^{*}$} & [13.615] \\
\hline \multirow[t]{2}{*}{ Season 1994} & & & & 11.331 & 26.741 & 27.731 & 17.345 \\
\hline & & & & {$[9.723]$} & {$[12.661]^{*}$} & {$[13.905]$} & [13.752] \\
\hline \multirow[t]{2}{*}{ Season 1995} & & & & -6.867 & 8.704 & 2.258 & -5.663 \\
\hline & & & & [10.137] & {$[10.861]$} & [12.648] & [12.604] \\
\hline \multirow[t]{2}{*}{ Season 1996} & & & & -3.987 & 10.932 & 10.382 & 3.116 \\
\hline & & & & {$[11.849]$} & {$[11.045]$} & [12.849] & [12.640] \\
\hline \multirow[t]{2}{*}{ Season 1997} & & & & 16.771 & 31.769 & 35.367 & 22.131 \\
\hline & & & & {$[10.258]$} & {$[10.449]^{* *}$} & {$[13.509]^{*}$} & [13.315] \\
\hline \multirow[t]{2}{*}{ Season 1998} & & & & 37.015 & 52.091 & 52.804 & 38.688 \\
\hline & & & & {$[11.685]^{* *}$} & {$[11.569]^{* *}$} & {$[14.016]^{* *}$} & {$[14.257]^{* *}$} \\
\hline \multirow{2}{*}{ Season 1999} & & & & 32.325 & 47.976 & 49.729 & 34.726 \\
\hline & & & & {$[11.684]^{* *}$} & {$[11.139]^{* *}$} & {$[13.501]^{* *}$} & {$[14.026]^{*}$} \\
\hline \multirow[t]{2}{*}{ Season 2000} & & & & 32.157 & 47.138 & 46.677 & 33.973 \\
\hline & & & & {$[13.980]^{*}$} & {$[13.388]^{* *}$} & {$[15.975]^{* *}$} & {$[16.139]^{*}$} \\
\hline $\begin{array}{l}\text { controls } \\
\text { rel. strength }\end{array}$ & No & No & No & No & Yes & Yes & Yes \\
\hline Home Team & No & No & No & No & No & Yes & Yes \\
\hline \multicolumn{8}{|l|}{ Fixed Eff. } \\
\hline \multirow{2}{*}{$\begin{array}{l}\text { Visitor Team } \\
\text { Fixed Eff. }\end{array}$} & No & No & No & No & No & Yes & Yes \\
\hline & & & & & & & \\
\hline $\begin{array}{l}\text { Referee } \\
\text { Fixed Eff. }\end{array}$ & No & No & No & No & No & No & Yes \\
\hline \multirow[t]{2}{*}{ Constant } & 124.077 & 72.592 & 65.975 & 84.524 & 63.594 & 82.614 & 108.493 \\
\hline & {$[4.584]^{* *}$} & {$[11.835]^{* *}$} & {$[11.765]^{* *}$} & {$[12.066]^{* *}$} & {$[17.761]^{* *}$} & {$[21.203]^{* *}$} & {$[23.102]^{* *}$} \\
\hline Observations & 895 & 893 & 893 & 893 & 844 & 844 & 844 \\
\hline R-squared & 0.02 & 0.05 & 0.08 & 0.14 & 0.16 & 0.22 & 0.34 \\
\hline
\end{tabular}

Notes:

1. Standard errors are in parentheses. One (two) asterisk(s) denotes significance at the 5 percent level (1 percent level). Standard errors allow for correlation between observations of the same referee.

2. The control variables "No. Treatments", "No. Substitution", "No. Yellow Cards", "No. 2nd Yellow", "No. Red Cards", sum the total number of respective events in the second half. When the number of any such event for the home and visiting team is controlled for separately, differences in coefficient estimates are very small and always statistically insignificant. Moreover, all other parameter estimates are robust to such specification changes.

3. The effect of adding a regressor for the number of fouls was small (less than one second) all specifications. Since this variable is highly correlated (correlation coefficient of 0.8) with the number of injury treatments, the specifications shown in the table are preferred.

4. Controls for relative strength include the relative number of tackles won, shots on goal, fouls, corner kicks and crosses as well as the absolute difference in rankings before the match and the ranking of the home team. None of these variables are significant. The hypothesis that controls for relative strength are jointly significant is strongly rejected by a Wald test at any reasonable significance level (p-value exceeds .7 in all specifications). Measures on which controls of relative strengths are based are missing for the majority of matches in the season 1992/93, which explains differences in observations used across columns. 
Table 2: Length of First-Half Injury Time in Close Games

The dependent variable is the length of first-half injury time (in seconds) in matches in which one team was leading by one goal after regular time. "Home Ahead" takes the value 1 if the home team is one goal ahead and zero if the home team is one goal behind.

\begin{tabular}{|c|c|c|c|c|c|c|c|}
\hline & {$[1]$} & {$[2]$} & {$[3]$} & {$[4]$} & {$[5]$} & {$[6]$} & {$[7]$} \\
\hline \multirow[t]{2}{*}{ Home Ahead } & -7.374 & -6.873 & -7.532 & -7.75 & -9.066 & -8.165 & -9.485 \\
\hline & {$[3.965]$} & {$[3.804]$} & {$[3.880]$} & {$[3.902]$} & {$[4.170]^{*}$} & {$[4.379]$} & {$[4.515]^{*}$} \\
\hline \multirow[t]{2}{*}{ No. Treatments } & & 1.714 & 1.219 & 1.167 & 1.312 & 1.526 & 1.856 \\
\hline & & {$[0.304]^{* *}$} & {$[0.276]^{* *}$} & {$[0.318]^{* *}$} & {$[0.337]^{* *}$} & {$[0.358]^{* *}$} & {$[0.381]^{* *}$} \\
\hline \multirow{2}{*}{ No. Substitution } & & 22.262 & 20.954 & 21.138 & 20.885 & 21.262 & 19.572 \\
\hline & & {$[3.345]^{* *}$} & {$[3.352]^{* *}$} & {$[3.322]^{* *}$} & {$[3.329]^{* *}$} & {$[3.647]^{* *}$} & {$[3.596]^{* *}$} \\
\hline \multirow[t]{2}{*}{ No. Yellow Cards } & & & 4.716 & 4.991 & 5.023 & 4.863 & 4.683 \\
\hline & & & {$[1.565]^{* *}$} & {$[1.566]^{* *}$} & {$[1.577]^{* *}$} & {$[1.711]^{* *}$} & {$[1.378]^{* *}$} \\
\hline \multirow[t]{2}{*}{ No. 2nd Yellow } & & & 17.807 & 17.478 & 15.475 & 15.98 & 12.832 \\
\hline & & & {$[6.460]^{* *}$} & {$[6.651]^{*}$} & {$[6.583]^{*}$} & {$[6.559]^{*}$} & [7.912] \\
\hline \multirow[t]{2}{*}{ No. Red Cards } & & & 31.656 & 30.429 & 36.485 & 39.82 & 40.557 \\
\hline & & & {$[8.749]^{* *}$} & {$[9.014]^{* *}$} & {$[8.849]^{* *}$} & {$[8.495]^{* *}$} & {$[8.536]^{* *}$} \\
\hline \multirow[t]{2}{*}{ Season 1993} & & & & 1.903 & -2.936 & 1.878 & -8.802 \\
\hline & & & & {$[6.279]$} & {$[8.921]$} & {$[8.442]$} & [8.672] \\
\hline \multirow[t]{2}{*}{ Season 1994} & & & & -6.755 & -12.135 & -5.309 & -17.199 \\
\hline & & & & {$[6.635]$} & {$[9.134]$} & {$[8.644]$} & [10.042] \\
\hline \multirow[t]{2}{*}{ Season 1995} & & & & -17.724 & -23.004 & -20.604 & -35.893 \\
\hline & & & & {$[6.003]^{* *}$} & {$[8.361]^{* *}$} & {$[8.574]^{*}$} & {$[9.215]^{* *}$} \\
\hline \multirow[t]{2}{*}{ Season 1996} & & & & -9.405 & -15.613 & -11.71 & -24.897 \\
\hline & & & & {$[6.836]$} & {$[9.722]$} & [9.909] & {$[11.426]^{*}$} \\
\hline \multirow[t]{2}{*}{ Season 1997} & & & & -18.364 & -22.83 & -17.846 & -33.393 \\
\hline & & & & {$[6.335]^{* *}$} & {$[8.790]^{*}$} & {$[9.232]$} & {$[11.036]^{* *}$} \\
\hline \multirow[t]{2}{*}{ Season 1998} & & & & -7.045 & -12.923 & -8.005 & -26.407 \\
\hline & & & & {$[5.951]$} & [8.165] & {$[8.902]$} & {$[9.948]^{*}$} \\
\hline \multirow[t]{2}{*}{ Season 1999} & & & & 2.389 & -2.981 & 4.545 & -10.692 \\
\hline & & & & {$[11.821]$} & [13.948] & {$[16.624]$} & [16.195] \\
\hline \multirow[t]{2}{*}{ Season 2000} & & & & -20.143 & -25.396 & -20.204 & -42.703 \\
\hline & & & & {$[6.755]^{* *}$} & {$[8.560]^{* *}$} & {$[9.343]^{*}$} & {$[10.542]^{* *}$} \\
\hline \multirow{2}{*}{$\begin{array}{l}\text { controls } \\
\text { rel. strength }\end{array}$} & No & No & No & No & Yes & Yes & Yes \\
\hline & & & & & & & \\
\hline $\begin{array}{l}\text { Home Team } \\
\text { Fixed Fff }\end{array}$ & No & No & No & No & No & Yes & Yes \\
\hline \multirow{2}{*}{$\begin{array}{l}\text { Visitor Team } \\
\text { Fixed Eff. }\end{array}$} & $\mathrm{No}$ & $\mathrm{No}$ & $\mathrm{No}$ & $\mathrm{No}$ & $\mathrm{No}$ & Yes & Yes \\
\hline & & & & & & & \\
\hline \multirow{2}{*}{$\begin{array}{l}\text { Referee } \\
\text { Fixed Eff. }\end{array}$} & No & No & No & No & No & No & Yes \\
\hline & & & & & & & \\
\hline \multirow[t]{2}{*}{ Constant } & 72.313 & 30.316 & 30.626 & 39.743 & 52.144 & 24.605 & 43.09 \\
\hline & {$[3.308]^{* *}$} & {$[6.134]^{* *}$} & {$[6.122]^{* *}$} & {$[8.367]^{* *}$} & {$[11.431]^{* *}$} & {$[14.211]$} & {$[18.304]^{*}$} \\
\hline Observations & 1183 & 1183 & 1183 & 1183 & 1091 & 1091 & 1091 \\
\hline R-squared & 0.00 & 0.07 & 0.1 & 0.12 & 0.13 & 0.18 & 0.28 \\
\hline
\end{tabular}

Notes:

1. Standard errors are in parentheses. One (two) asterisk(s) denotes significance at the 5 percent level (1 percent level). Standard errors allow for correlation between observations of the same referee.

2. The control variables "No. Treatments", "No. Substitution", "No. Yellow Cards", "No. 2nd Yellow", "No. Red Cards", sum the total number of respective events in the second half. When the number of any such event for the home and visiting team is controlled for separately, differences in coefficient estimates are very small and always statistically insignificant. Moreover, all other parameter estimates are robust to such specification changes.

3. The effect of adding a regressor for the number of fouls was small (less than one second) all specifications. Since this variable is highly correlated (correlation coefficient of 0.8) with the number of injury treatments, the specifications shown in the table are preferred.

4. Controls for relative strength include the relative number of tackles won, shots on goal, fouls, corner kicks and crosses as well as the absolute difference in rankings before the match and the ranking of the home team. Only the rank of the home team is marginally significant $(\mathrm{p}$-value $=.1)$ in one specification. The hypothesis that controls for relative strength are jointly significant is strongly rejected by a Wald test at any reasonable significance level (p-value exceeds .1 in all specifications). Measures on which controls of relative strengths are based are missing for the majority of matches in the season 1992/93, which explains differences in observations used across columns. 
Table 3: Length of Second-Half Injury Time in Drawn Matches

The dependent variable is the length of second-half injury time in drawn matches.

\begin{tabular}{|c|c|c|c|c|c|}
\hline & {$[1]$} & {$[2]$} & {$[3]$} & {$[4]$} & {$[5$.} \\
\hline Home Tied & & $\begin{array}{r}9.199 \\
{[6.053]}\end{array}$ & $\begin{array}{r}4.05 \\
{[7.153]}\end{array}$ & & \\
\hline 0:0 Score & & & $\begin{array}{l}-8.078 \\
{[4.827]}\end{array}$ & $\begin{array}{l}-10.088 \\
{[4.132]^{*}}\end{array}$ & $\begin{array}{r}-11.576 \\
{[4.074]^{* *}}\end{array}$ \\
\hline No. Treatments & $\begin{array}{r}1.356 \\
{[0.543]^{*}}\end{array}$ & $\begin{array}{r}1.341 \\
{[0.529]^{*}}\end{array}$ & $\begin{array}{r}1.25 \\
{[0.526]^{*}}\end{array}$ & $\begin{array}{r}1.26 \\
{[0.534]^{*}}\end{array}$ & $\begin{array}{r}1.347 \\
{[0.553]^{*}}\end{array}$ \\
\hline No. Substitutions & $\begin{array}{r}4.823 \\
{[2.657]}\end{array}$ & $\begin{array}{r}4.625 \\
{[2.584]}\end{array}$ & $\begin{array}{r}4.167 \\
{[2.476]}\end{array}$ & $\begin{array}{r}4.194 \\
{[2.486]}\end{array}$ & $\begin{array}{r}4.507 \\
{[2.547]}\end{array}$ \\
\hline No. Yellow Cards & $\begin{array}{r}5.597 \\
{[1.708]^{* *}}\end{array}$ & $\begin{array}{r}5.541 \\
{[1.683]^{* *}}\end{array}$ & $\begin{array}{r}5.859 \\
{[1.770]^{* *}}\end{array}$ & $\begin{array}{r}5.848 \\
{[1.780]^{* *}}\end{array}$ & $\begin{array}{r}5.378 \\
{[1.753]^{* *}}\end{array}$ \\
\hline No. 2nd Yellow & $\begin{array}{r}12.425 \\
{[5.435]^{*}}\end{array}$ & $\begin{array}{r}11.757 \\
{[5.579]^{*}}\end{array}$ & $\begin{array}{r}13.247 \\
{[5.501]^{*}}\end{array}$ & $\begin{array}{r}13.363 \\
{[5.414]^{*}}\end{array}$ & $\begin{array}{r}11.294 \\
{[5.288]^{*}}\end{array}$ \\
\hline No. Red Cards & $\begin{array}{r}8.135 \\
{[8.835]}\end{array}$ & $\begin{array}{r}7.206 \\
{[8.927]}\end{array}$ & $\begin{array}{r}8.117 \\
{[9.006]}\end{array}$ & $\begin{array}{r}8.481 \\
{[8.795]}\end{array}$ & $\begin{array}{r}7.959 \\
{[8.846]}\end{array}$ \\
\hline Rank Difference & $\begin{array}{r}0.988 \\
{[0.592]}\end{array}$ & $\begin{array}{r}0.97 \\
{[0.591]}\end{array}$ & $\begin{array}{r}0.948 \\
{[0.592]}\end{array}$ & $\begin{array}{r}0.951 \\
{[0.592]}\end{array}$ & $\begin{array}{r}0.98 \\
{[0.590]}\end{array}$ \\
\hline Rank of Home Team & $\begin{array}{r}0.342 \\
{[0.524]}\end{array}$ & $\begin{array}{r}0.331 \\
{[0.522]}\end{array}$ & $\begin{array}{r}0.2 \\
0.524]\end{array}$ & $\begin{array}{r}0.209 \\
{[0.524]}\end{array}$ & $\begin{array}{r}0.374 \\
{[0.522}\end{array}$ \\
\hline Rel. Tackles Won & $\begin{array}{r}-77.08 \\
{[70.623]}\end{array}$ & $\begin{array}{l}-84.751 \\
{[70.592}\end{array}$ & $\begin{array}{r}-84.025 \\
{[70.448}\end{array}$ & $\begin{array}{l}-81.095 \\
{[70.299}\end{array}$ & $\begin{array}{r}-80.846 \\
{[70.403}\end{array}$ \\
\hline Rel. Shots on Goal & $\begin{array}{r}45.78 \\
{[23.751]}\end{array}$ & $\begin{array}{r}46.024 \\
{[23.700]}\end{array}$ & $\begin{array}{r}44.212 \\
{[24.004]}\end{array}$ & $\begin{array}{r}45.286 \\
{[23.947]}\end{array}$ & $\begin{array}{r}53.171 \\
{[23.903]^{*}}\end{array}$ \\
\hline Rel. Fouls & $\begin{array}{r}-67.794 \\
{[29.795]^{*}}\end{array}$ & $\begin{array}{r}-64.899 \\
{[29.772]^{*}}\end{array}$ & $\begin{array}{r}-69.241 \\
{[29.745] *}\end{array}$ & $\begin{array}{r}-70.938 \\
{[29.639]^{*}}\end{array}$ & $\begin{array}{r}-69.986 \\
{[29.710]^{*}}\end{array}$ \\
\hline Rel. Corners & $\begin{array}{r}17.318 \\
{[14.906]}\end{array}$ & $\begin{array}{r}14.206 \\
{[14.968]}\end{array}$ & $\begin{array}{r}16.293 \\
{[14.916]}\end{array}$ & $\begin{array}{r}17.268 \\
{[14.847]}\end{array}$ & $\begin{array}{r}14.968 \\
{[14.893}\end{array}$ \\
\hline Rel. Crosse & $\begin{array}{r}16.454 \\
{[19.608}\end{array}$ & $\begin{array}{r}11.792 \\
{[19.726]}\end{array}$ & $\begin{array}{r}12.056 \\
{[19.621]}\end{array}$ & $\begin{array}{r}13.728 \\
{[19.474]}\end{array}$ & $\begin{array}{r}14.46 \\
{[19.562}\end{array}$ \\
\hline No. Tackles & & & $\begin{array}{r}0.18 \\
{[0.067]^{* *}}\end{array}$ & $\begin{array}{r}0.18 \\
{[0.066]^{* *}}\end{array}$ & \\
\hline $\begin{array}{l}\text { No. Shots } \\
\text { on goal }\end{array}$ & & & $\begin{array}{r}0.604 \\
{[0.502]}\end{array}$ & $\begin{array}{r}0.626 \\
{[0.490]}\end{array}$ & \\
\hline No. Crosses & & & $\begin{array}{r}0.406 \\
{[0.396]}\end{array}$ & $\begin{array}{r}0.416 \\
{[0.395}\end{array}$ & \\
\hline Constant & $\begin{array}{r}-9.967 \\
{[23.162]}\end{array}$ & $\begin{array}{r}-8.646 \\
{[22.526]}\end{array}$ & $\begin{array}{r}-54.055 \\
{[28.079]}\end{array}$ & $\begin{array}{r}-53.605 \\
{[28.138]}\end{array}$ & $\begin{array}{r}-0.419 \\
{[22.192]}\end{array}$ \\
\hline Obse & 709 & 709 & 709 & 709 & 709 \\
\hline R-squared & 0.39 & 0.39 & 0.40 & 0.40 & 0.39 \\
\hline
\end{tabular}

Notes:

1. All regressions include season dummies, team dummies and referee dummies.

2. Standard errors are in parentheses. One (two) asterisk(s) denotes significance at the 5 percent level (1 percent level). Standard errors allow for correlation between observations of the same referee.

3. Relative (Rel.) measures for an event $X$ are calculated as the ratio of the number of $\mathrm{X}$ for home team to the total number of $\mathrm{X}$ minus 0.5 and are therefore positive when the home team has had more of the events than the visiting team. 
Table 4: Individual Bias

\begin{tabular}{c|ccc|ccc}
\hline Home Bias & \multicolumn{3}{|c|}{ Home Behind } & \multicolumn{3}{c}{ Home Ahead } \\
in Seconds & mean & st.d. & Number & mean & st.d. & Number \\
\hline-18.2 & 23.8 & 60.0 & 14 & 42.0 & 49.1 & 25 \\
-9.0 & -3.0 & 68.3 & 17 & 6.1 & 59.6 & 28 \\
-1.7 & 11.3 & 29.4 & 10 & 13.0 & 59.4 & 15 \\
1.6 & -4.6 & 28.6 & 10 & -6.2 & 58.5 & 21 \\
2.5 & -4.1 & 51.1 & 10 & -6.6 & 52.8 & 21 \\
2.6 & 13.2 & 20.0 & 5 & 10.7 & 60.6 & 12 \\
10.4 & 9.8 & 56.1 & 13 & -0.6 & 48.3 & 17 \\
10.7 & 12.5 & 70.4 & 7 & 1.8 & 27.6 & 9 \\
12.5 & -14.6 & 42.0 & 15 & -27.1 & 43.5 & 29 \\
18.2 & 10.1 & 102.6 & 8 & -8.04 & 70.4 & 13 \\
21.6 & -0.1 & 45.0 & 5 & -21.6 & 33.5 & 15 \\
24.0 & -4.6 & 57.5 & 9 & -28.6 & 64.2 & 18 \\
26.3 & 8.7 & 81.8 & 24 & -17.6 & 70.5 & 28 \\
26.9 & 8.5 & 57.9 & 11 & -18.4 & 54.7 & 20 \\
33.8 & 48.3 & 66.2 & 14 & 14.5 & 63.9 & 15 \\
36.0 & 15.4 & 48.9 & 22 & -20.5 & 40.2 & 24 \\
38.5 & 3.0 & 45.9 & 18 & -35.5 & 35.5 & 23 \\
46.0 & 13.3 & 61.7 & 6 & -32.7 & 40.2 & 9 \\
47.0 & 34.0 & 58.8 & 26 & -13.1 & 37.2 & 28 \\
47.2 & 58.3 & 64.9 & 18 & 11.1 & 29.2 & 17 \\
49.6 & 30.7 & 44.8 & 6 & -18.9 & 48.1 & 15 \\
50.6 & 36.5 & 60.4 & 11 & -14.2 & 51.4 & 14 \\
\hline
\end{tabular}

Notes: The table shows the difference between the average length of additional time that individual referees who have umpired at least 5 games in which the home team was behind and five games in which the home team was ahead award in the two situations. The reported means are means of residuals from the regression in column [6] of Table 1. Hence, the reported bias is the bias that remains after controlling for the variables in Table 1. 
Table 5: The Stadium, the Crowd, and 2nd Half Injury Time in Close GAMES

The dependent variable is the length of injury time awarded at the end of the match in matches where the home team is either one goal behind (Score Difference=-1) or one goal ahead (Score Difference=1). The sample is split into matches that take place in stadiums without a track separating the field and the stands (columns 1 and 2) and matches in stadiums with a track (columns 3 and 4 ).

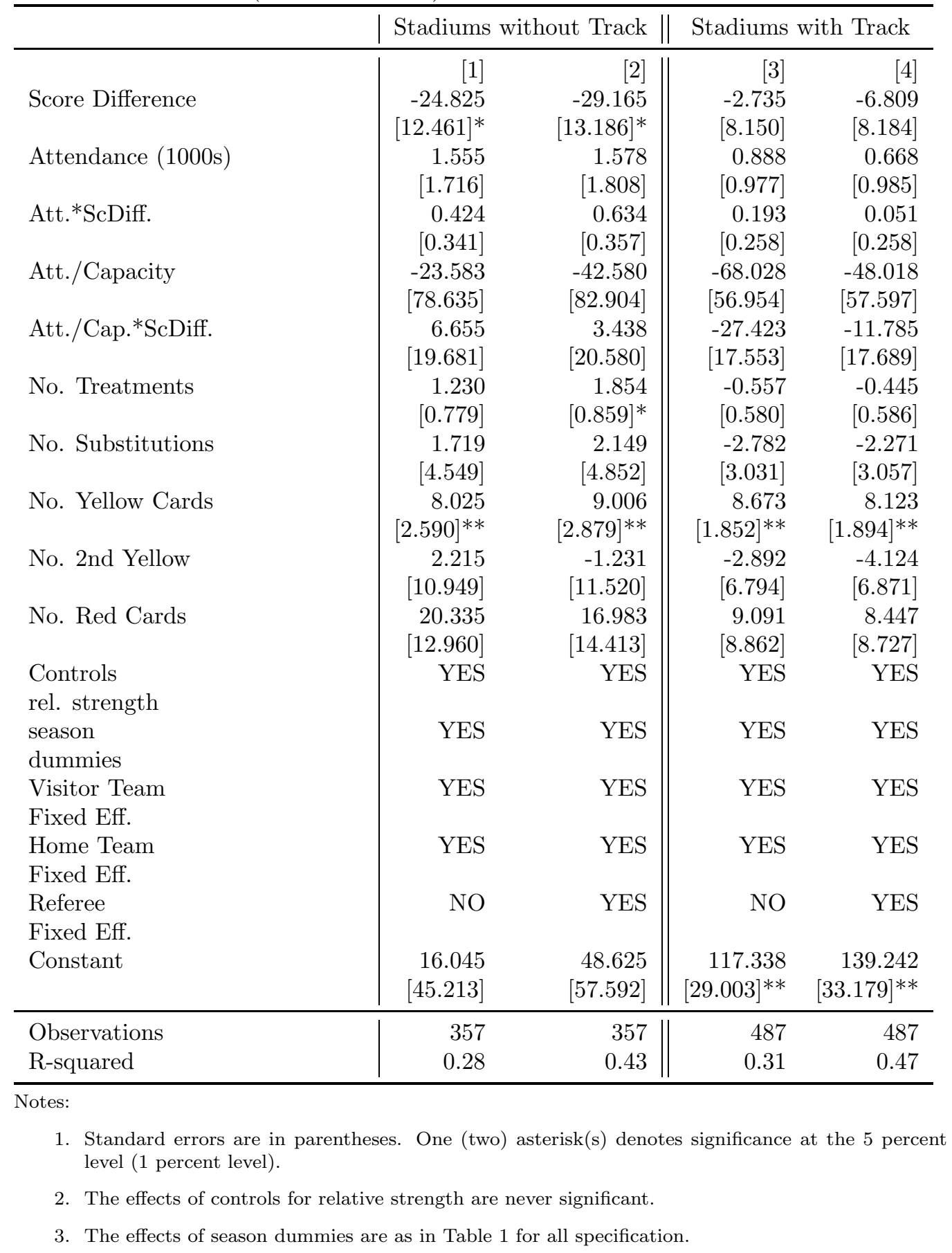


Table 6: Attendance of Games

The dependent variable is the deviation from average attendance

\begin{tabular}{ll|rl}
\hline Distance: & less than $150 \mathrm{~km}$ & 4.906 & {$[0.459]^{* *}$} \\
& $150 \mathrm{~km}-300 \mathrm{~km}$ & 0.818 & {$[0.418]$} \\
& more than $450 \mathrm{~km}$ & -0.258 & {$[0.425]$} \\
Attractiveness of Visitor & & 50.848 & {$[1.683]^{* *}$} \\
Constant & & -33.647 & {$[1.106]^{* *}$} \\
\hline Observations & 2754 & \\
R-squared & 0.28 & \\
\hline
\end{tabular}

Notes:

1. The variable "Distance" measures the shortest distance between the home cities of opponents. The attractiveness of the visitor is calculated as the average attendance to capacity ratio in all away games except those that are played on the current opponent's turf.

2. Standard errors are in parentheses. One (two) asterisk(s) denotes significance at the 5 percent level (1 percent level).

3. The effects of controls for relative strength are never significant.

4. To avoid correlation between explanatory variables and the disturbance term of the regression, the attractiveness of the visitor is calculated as the average attendance to capacity ratio when the visitor plays abroad excluding the matches against the home team. Similarly, the average attendance has been calculated over all home matches except for those against the current opponent. 
Table 7: Crowd Composition Effects in Close Games

The dependent variable second-half injury time in close matches

\begin{tabular}{l|ll}
\hline & {$[1]$} & {$[2]$} \\
\hline Score Difference & 0.387 & -14.977 \\
& {$[12.179]$} & {$[3.131]^{* *}$} \\
Attraction*Score Diff. & -3.948 & 9.872 \\
& {$[18.322]$} & {$[5.010]^{*}$} \\
\hline Observations & 151 & 693 \\
R-squared & 0.67 & 0.38 \\
\hline
\end{tabular}

Notes:

1. Standard errors are in parentheses. One (two) asterisk(s) denotes significance at the 5 percent level (1 percent level).

2. The regressions include controls for the number of treatments, substitutions and cars, controls for relative strength, season dummies, referee dummies and team dummies.

3. The variable "Attraction*Score Diff." is the interaction between the "Score Difference" variable and a dummy that takes the value 1 if the visiting team is in the top third of the ranking according to the proxied relative composition of the crowd. The latter variable is the ratio of the average attractiveness of the visitor (see Table 6) to the average attendance to capacity ratio in home games of the home team. 
Table 8: Penalty Kick Decisions for the Home Team

\begin{tabular}{l|lll|l}
\hline $\begin{array}{l}\text { Score } \\
\text { Difference }\end{array}$ & wrong & $\begin{array}{c}\text { Decision } \\
\text { correct }\end{array}$ & $\begin{array}{l}\text { Absolute } \\
\text { Number }\end{array}$ \\
\hline$\leq-3$ & 33.33 & 50.00 & 16.67 & 6 \\
-2 & 4.35 & 47.83 & 47.83 & 23 \\
-1 & 11.22 & 66.33 & 22.45 & 98 \\
0 & 4.95 & 64.85 & 30.20 & 202 \\
1 & 5.26 & 71.58 & 23.16 & 95 \\
2 & 5.13 & 74.36 & 20.51 & 39 \\
$\geq 3$ & 0.00 & 88.89 & 11.11 & 27 \\
\hline Total & 6.33 & 67.55 & 26.12 & 490 \\
\hline
\end{tabular}

Table 9: Penalty Kick Decisions for the Visiting Team

\begin{tabular}{l|lll|l}
\hline $\begin{array}{l}\text { Score } \\
\text { Difference }\end{array}$ & wrong & $\begin{array}{c}\text { Decision } \\
\text { correct }\end{array}$ & disputable & $\begin{array}{l}\text { Absolute } \\
\text { Number }\end{array}$ \\
\hline$\leq-3$ & 16.67 & 66.67 & 16.67 & 6 \\
-2 & 33.33 & 66.67 & 0.00 & 3 \\
-1 & 0.00 & 96.00 & 4.00 & 25 \\
0 & 7.45 & 68.09 & 24.47 & 94 \\
1 & 5.48 & 64.38 & 30.14 & 73 \\
2 & 4.17 & 79.17 & 16.67 & 24 \\
$\geq 3$ & 6.67 & 73.33 & 20.00 & 15 \\
\hline Total & 6.25 & 71.25 & 22.50 & 240 \\
\hline
\end{tabular}




\section{IZA Discussion Papers}

\begin{tabular}{|c|c|c|c|c|}
\hline No. & Author(s) & Title & Area & Date \\
\hline 739 & M. Fertig & $\begin{array}{l}\text { Who's to Blame? The Determinants of German } \\
\text { Students' Achievement in the PISA } 2000 \text { Study }\end{array}$ & 1 & $03 / 03$ \\
\hline 740 & $\begin{array}{l}\text { B. T. Hirsch } \\
\text { S. L. Mehay }\end{array}$ & $\begin{array}{l}\text { Evaluating the Labor Market Performance of } \\
\text { Veterans Using a Matched Comparison Group } \\
\text { Design }\end{array}$ & 6 & $03 / 03$ \\
\hline 741 & $\begin{array}{l}\text { B. T. Hirsch } \\
\text { D. A. Macpherson }\end{array}$ & $\begin{array}{l}\text { Wages, Sorting on Skill, and the Racial } \\
\text { Composition of Jobs }\end{array}$ & 5 & $03 / 03$ \\
\hline 742 & R. A. Easterlin & Building a Better Theory of Well-Being & 3 & $03 / 03$ \\
\hline 743 & $\begin{array}{l}\text { G. Heineck } \\
\text { J. Schwarze }\end{array}$ & $\begin{array}{l}\text { Substance Use and Earnings: The Case of } \\
\text { Smokers in Germany }\end{array}$ & 5 & $03 / 03$ \\
\hline 744 & $\begin{array}{l}\text { M. R. West } \\
\text { L. Woessmann }\end{array}$ & $\begin{array}{l}\text { Which School Systems Sort Weaker Students } \\
\text { into Smaller Classes? International Evidence }\end{array}$ & 2 & $03 / 03$ \\
\hline 745 & L. Woessmann & $\begin{array}{l}\text { Educational Production in East Asia: The Impact } \\
\text { of Family Background and Schooling Policies on } \\
\text { Student Performance }\end{array}$ & 2 & $03 / 03$ \\
\hline 746 & $\begin{array}{l}\text { A. Ammermueller } \\
\text { H. Heijke } \\
\text { L. Woessmann }\end{array}$ & $\begin{array}{l}\text { Schooling Quality in Eastern Europe: } \\
\text { Educational Production During Transition }\end{array}$ & 4 & $03 / 03$ \\
\hline 747 & J. Messina & Sectoral Structure and Entry Regulations & 3 & $03 / 03$ \\
\hline 748 & M. Pflüger & $\begin{array}{l}\text { Economic Integration, Wage Policies and Social } \\
\text { Policies }\end{array}$ & 2 & $04 / 03$ \\
\hline 749 & $\begin{array}{l}\text { V. Jakobsen } \\
\text { N. Smith }\end{array}$ & $\begin{array}{l}\text { The Educational Attainment of the Children of } \\
\text { the Danish 'Guest Worker' Immigrants }\end{array}$ & 1 & $04 / 03$ \\
\hline 750 & $\begin{array}{l}\text { R. Hujer } \\
\text { M. Caliendo } \\
\text { S. Thomsen }\end{array}$ & $\begin{array}{l}\text { New Evidence on the Effects of Job Creation } \\
\text { Schemes in Germany - A Matching Approach } \\
\text { with Threefold Heterogeneity }\end{array}$ & 6 & $04 / 03$ \\
\hline 751 & $\begin{array}{l}\text { L. Borghans } \\
\text { B. ter Weel }\end{array}$ & $\begin{array}{l}\text { Are Computer Skills the New Basic Skills? The } \\
\text { Returns to Computer, Writing and Math Skills in } \\
\text { Britain }\end{array}$ & 5 & $04 / 03$ \\
\hline 752 & $\begin{array}{l}\text { N. Malchow-Møller } \\
\text { J. R. Skaksen }\end{array}$ & $\begin{array}{l}\text { Skill-Biased Technological Change in Denmark: } \\
\text { A Disaggregate Perspective }\end{array}$ & 5 & $04 / 03$ \\
\hline 753 & $\begin{array}{l}\text { S. Burgess } \\
\text { H. Turon }\end{array}$ & $\begin{array}{l}\text { Unemployment Equilibrium and On-the-Job } \\
\text { Search }\end{array}$ & 1 & $04 / 03$ \\
\hline 754 & H. Turon & $\begin{array}{l}\text { Separability of Duration Dependence and } \\
\text { Unobserved Heterogeneity }\end{array}$ & 1 & $04 / 03$ \\
\hline 755 & T. Dohmen & $\begin{array}{l}\text { In Support of the Supporters? Do Social Forces } \\
\text { Shape Decisions of the Impartial? }\end{array}$ & 7 & $04 / 03$ \\
\hline
\end{tabular}

An updated list of IZA Discussion Papers is available on the center's homepage www.iza.org. 